\title{
Primary Investigation into \\ Management Ethical Thoughts by Lao Tzu
}

\author{
Fengguang Ma \\ School of Business Administration, Jiangsu University \\ Zhenjiang 212013, Jiangsu, China \\ E-mail: mfg3@sina.com
}

\begin{abstract}
Thoughts of Lao Tzu contain a great variety of management ethical thoughts. The leadership codes of ethics of "kindness, thrift and not being the trailblazer" and the "ethical management mode of "governing by doing nothing that is against nature" inspire contemporary managers to lay importance on ethical management, soft management and green management.
\end{abstract}

\section{Keywords: Lao Tzu, Management ethics, Ethical management}

In western countries, since 1960s, especially since the period after 1980s, integration of two originally irrelevant fields---management and ethics has become more and more obvious, which has a profound and great effect upon management thoughts. Some scholars even describe the phenomenon as "a revolution in management thoughts". (Note 1) In the past few years, the Chinese former President Jiang Zemin pointed out that, we should not only govern the country according to law, but should run the country with morality. In the process of implementation of running the country with morality, we should derive nutrition from our own culture.

In Chinese traditional culture, doctrines of Lao Tzu have received extreme favor from contemporary human being. In 1987, the American President Reagan quoted one sentence in $<<$ Tao Te Ching $>>$ by Lao Tzu in his State of the Union Address, that is, "ruling a great nation just like cooking a small delicacy", which has become a philosophical maxim by some Americans. (Note 2) Some people regard doctrine of Lao Tzu as "kingcraft and philosophy of politics". However, from a current perspective, it actually contains a great variety of management thoughts.

Lao Tzu has said "There are four supreme elements in the universe and human being is one" (Chapter 25). Management thoughts of Lao Tzu involve relationship between human being and the nature and relationship between human beings, and this article is going to make initial discussion on them.

1.

Lao Tzu has said "only when the great nature is abandoned, is it necessary to advocate humaneness and righteousness" (Chapter 18) and "“etiquette' is the outcome of insufficient faith and the beginning of disastrous disorder" (Chapter 38). However, Lao Tzu was not an ethical nihilist, and he just sighed with a cynical emotion about the fact that some people pursued moral reclame but ignored its essence and even strived for personal interest in the guise of morality. As a matter of fact, Lao Tzu paid great attention to ethical culture of managers, and he advocated cultivating the morality and executing rule of virtue. He said, "Beautiful words can win others' respect and polite behavior can receive others' attention" (Chapter 62) and "The nature has no preference to any one and always helps those honest well-doers" (Chapter 79). If managers are on the straight, it is natural they win others' respect and support. "To put the principle onto oneself, one's virtue will be actual and pure; to put the principle onto one's family, his virtue will be plentiful and superabundant; to put the principle onto one's town, his virtue will be respected; to put the principle upon one's country, his virtue will be enormous; to put the principle onto the world, his virtue will become popular without limit" (Chapter 54). Managers should cultivate themselves with morality, keep their family in order with morality, govern their countries with morality and bring peace to the world with morality.

Lao Tzu put forward three most important ethical codes of management --- "The first code is kindness, the second is thrift and the third code is not being the trailblazer" (Chapter 67).

The so-called "kindness" refers to generosity. According to Lao Tzu, "lofty morality akins to a ravine" (Chapter 41), 
that is, like a ravine which is tolerant and munificent. "Those who are aware of the nature are all embracive, which in turn means frankness and fairness; fairness means comprehensiveness, which in turn corresponds with "Tao" in the nature, and then one can last for long" (Chapter 16). That is, if managers have a big heart, are open-minded and magnanimous, then they can remain invincible. Specifically speaking, first of all, managers should be good at holding together and relying on their subordinates. They should recruit more capable personnel, have sufficient trust in them, show concern with them and respect them, just as "The Big Sea is where all rivers converge because it always lies at a low position" (Chapter 66). Then, managers should tolerate others' advantages, and also their disadvantages. In other words, as managers, they should not only have the disposition to appreciate others' talents and allow others to surpass themselves, but should also forgive others' faults. Finally, managers should "treat well those kind and unkind" (Chapter 49). Even for those who are in conflict with themselves or those who have serious problems, they should also "render good for evil" (Chapter 63).

The so-called "thrift" refers to austerity. Lao Tzu said, "gay colors may make one dazzled; noisy tone may cause hearing loss; wonderful meal may confuse one's taste' racing and hunting may madden one's mind; rare articles may make one behave against the law" (Chapter 12). "Great wealth cannot be stored; if riches are overbearing, then they sow seeds of future trouble" (Chapter 9). "Excessive pursuit of fame and gain implies more cost; excessive accumulation of wealth causes more disastrous damage". Lao Tzu inspired people to ponder with heart, "reputation and life --- which one is more intimate? life and interest --- which one is more precious? gain and loss --- which one is more harmful?" He reminded further, "learn to be satisfied, then one will not feel humiliated; learn not to overdo things, then one will not be encountered with danger" (Chapter 44). "The biggest disaster is insatiability, and the biggest fault is greedy desire. Those who know when to be satisfied are always satisfied" (Chapter 46). When dealing with relations between fame and life, between fame and dignity, one should learn to be satisfied, and then one can settle down and get on with his pursuit. On the contrary, if managers are greedy and luxury and gather possessions by hook, then they will bring pain and disaster to themselves, and even invite self-destruction. Therefore, managers should "eliminate the extreme, luxury and excessive attitude" (Chapter 29), and "maintain a pure and earthy nature and get rid of the selfish desire" (Chapter 19). To pursue satisfaction of one's desire is normal, but desire should be restricted, and, what's more, managers should not pursue ill-gotten wealth.

The so-called "not being the trailblazer" means holding oneself aloof from worldly success. According to Lao Tzu, "a Saint usually has no thought of self" (Chapter 49), and "if a Saint intends to lead his people, then he must show his modesty to his people with words and puts his own interest behind them. Thus, although a Saint who has "Tao" occupies a higher status, his people don't feel heavily burdened; although he walks before his people, his people don't feel hurt" (Chapter 66). As a manager, one should always consider for others and put interest of common people at the first place. Furthermore, he should learn the spirit of water, that is, "moistening the world but not glomming on to it, nurturing the world but not being meritorious and leading the world but not dominating it" (Chapter 51). Although water makes everything, it "withdraws after success" (Chapter 9), and it would rather play a nameless role than strive for fame and gain. Lao Tzu also pointed out, "a Saint who has "Tao" is upright but not incondite, is angular but not harmful, is straightforward but not licentious, and is luculent but not dazzling" (Chapter 58). Thus, managers should not seek to prevail over others and should not even be arrogant and domineering. "When one has all, it is right time to stop; if one doesn't hide his light, then his advantages will not last long" (Chapter 9). When we conduct ourselves in the society, we should leave some leeway. Otherwise, we may hurt ourselves. As a manager, one should "hide his light, eliminate dispute, restrict his brilliance and mix himself into the earthliness" (Chapter 56), that is, to be one with the masses.

Actually, from the point of view of Lao Tzu, "no fight" is the embodiment of his thoughts of "weakness excelling power and mercy excelling force" (Chapter 78). The reason for Lao Tzu believing "as good as water" is not only that "water moistening the world but not contesting with it, and it suspends where the masses don't like to go, so it is more close to "Tao" (Chapter 8), but also that "there is nothing more fragile than water, but there is also nothing more capable than water in assaulting fortification" (Chapter 78). Thereout, water doesn't contest with the world, so there is nothing that can contest with it. In ancient times, it is said, "stooping to compromise" (Chapter 22). If a manager is charitable and doesn't seek fame and wealth, then he can free from complicated interpersonal disputes, establish a harmonious interpersonal relationship, and mould a positive personal image, which will leave more time and energy to put into his career and will gain trust and support from others. At the same time, that is helpful to create a healthy working atmosphere and to motivate enthusiasm in his subordinates. Of course, holding aloof from worldly success doesn't equal to confusing truth and falsehood, making no attempt and being content to be below others, but is finally for career development of the individual and his organization.

In addition to the above three virtues, Lao Tzu also put forward other moral standards. Such as:

1). Integrity. Lao Tzu said, "One should be honest, friendly and unselfish to others and his worlds should make the best of a bad bargain" (Chapter 8), "those who make easily a promise will seldom realize it" (Chapter 63), and "honest 
words are not beautiful and beautiful words are not honest" (Chapter 81). A manager should be honest to others. Otherwise, he will lose trust and respect from others.

2). Modesty. Lao Tzu said, "a wise man never has many words, but one with many words is not a wise man" (Chapter 56), "One who knows what he doesn't know is wise. One who pretends to know what he doesn't know in his own conceit is quite awful" (Chapter 71), and "a real egghead never shows off, but one who often shows off never knows a lot" (Chapter 81). One should not indulge in exaggerations, let alone claiming to know what he doesn't know. "One who regards himself as infallible never gets prominent; one who aggrandizes himself never achieves success; one who is egotistic can never be the best" (Chapter 24). As a manager, one shouldn't aggrandize himself, be fond of the limelight, and regard himself as infallible.

3). Pragmatic. There are two widely spread sayings by Lao Tzu, "when dealing with a problem, one should start from what is the easiest, and when preparing to realize a farseeing target, one should start from what is the subtlest. Hence, a Saint who has "Tao" never seeks after great contributions, so he can accomplish a great event" (Chapter 63). "A jointly held tree comes from exiguous sprout; a hathpace of nine layers comes from a pile of clay; a journey of a thousand miles begins with a single step". "When a matter comes to its end, it should be just as cautious as when it is started, and then nothing is impossible" (Chapter 64). A manager should be earnest and down-to-earth, begin well and end well, and shouldn't boil the ocean or have high aspirations but low abilities.

2.

Lao Tzu advocated "to govern a country by inaction and quietness" (Chapter 57). Then, what is "fairness"? According to Lao Tzu, "only quietness and inaction can govern a country" (Chapter 45), and "to govern a country by inaction and quietness" means "governing a country without disturbing its people" (Chapter 57), that is, "governing by non-interference". Lao Tzu classified operation into four levels, namely, "the best ruler is one whose existence are not known; the secondary ruler is one who is close to people and who is commended; a then inferior ruler is one who is feared; a worst ruler is one who is disdained" (Chapter 17). "Governing by non-inference" is the highest ideal for operation. Referring to words of Saints (here Saints from the perspective of Lao Tzu are the best managers), Lao Tzu described for us an ideal prospect in his eye, that is, "inaction, then people can educate themselves; quietness, then people are rich naturally; unselfishness, then people are unsophisticated naturally" (Chapter 57). Once it is successful, the ordinary people say, "we are supposed to be successful" (Chapter 17).

Governing by non-interference is the most characteristic and fantastic part of Lao Tzu's management thoughts. It has brought quite profound impacts on later generations, and quite lots of managers at all times and in all lands have been committed to mastering and applying it. The principal of American Bell laboratory, Dr. Chen Yiyao ascribed success to the thought of governing by non-interference. A banner of "Governing by non-interference" is put up on the wall of his office. He further explained, "the responsibility of a leader is not only to lead, but to make people feel that you are not intervening them". (Note 3) The requirements for thoughts of governing by non-interference are as follows:

\subsection{To let nature take its course}

To let nature take its course is the core of governing by non-interference. Lao Tzu said, "people follow the law of the earth, which follows the law of the heaven, which in turn follows the law of 'Tao', whereas Tao exactly follows the example of the nature" (Chapter 25). The so-called nature here refers to the objective law. Lao Tzu pointed out, "to be aware of the natural law is called intelligence, whereas a flighty behavior that is not aware of the natural law tends to cause disorder and disaster" (Chapter 16). That is to say, if a manager doesn't follow the law, and regards himself as infallible, then it is necessary that he will produce exactly the opposite results and gets punished by the law.

\subsection{Management mode should be magnanimous.}

Lao Tzu said, "if a politics is transparent, then its people are unsophisticated and loyal; if a politics is trenchant and tenebrous, then its people are crafty and querulous" (Chapter 58). That is to say, if a manger is large-minded, then his people are pure and honest; if a manager is too harsh and strict, then his people may become craft. Lao Tzu also said, "the more an ordinance is stern, the more cracksmen" (Chapter 57). If an ordinance is too harsh, then on the contrary, the bandits will give a lot of trouble.

\subsection{A leader should know how to judge and use people.}

Lao Tzu had a splendiferous metaphor, "ruling a great nation just like cooking a small delicacy" (Chapter 60). If a small fish is frequently churned when cooked, then its meat will become shreds; if a government order is too cockamamie and the government wades in everything, then effects of the subordinates may have a greatly reduced quality. Lao Tzu believed that, "no issue of government order and no disturb of the people corresponds to the nature" (Chapter 23), and "too many government orders may make people perplex, which won't work" (Chapter 5). To press the least is to manage the best, and to press too hard is to become more passive. Therefore, "a primordial object of austere can be made into a waref. A man with Tao who follows truth and plainness is the head of a hundred of rulers. Thus, a perfect 
politics is not indiscerptible" (Chapter 28). That is to say, a leader should take into consideration the overall situation, be aware of the direction, and let his subordinates deal with specific affairs, but should not be entangled in minor details.

To know how to judge and use people. Firstly, "a Saint who has Tao not only knows his distance, but also doesn't show off" (Chapter 72). A leader should not regard himself as infallible, but should have a level-headed recognition and correct appraisal to himself. He should be able to look in the eye all his disadvantages, and then he can unify and rely on others in his work. Secondly, "a Saint usually rescues its people, so there are no people discarded; he usually makes the best use of things, so there is nothing discarded. This is the so-called intelligence and wisdom hidden internally" (Chapter 27). A leader should come to realize that, just as he is not perfect himself, others can also not be perfect in every way. The key to employing a person is to maximize his favourable factors and to minimize his unfavourable factors. Thirdly, "those who are good at employing people are modest to others. This is a morality not to struggle with others, this is the ability to employ others and this corresponds with the nature" (Chapter 68). It is a responsibility for managers to provide a stage for members of an organization to display their ability and to create a good working environment for them. Only when a manager is courteous to the wise and condescending to the scholarly, and doesn't pay too much attention to gain and loss, then can he sufficiently tap his potential.

What should be pointed out here, "inaction" by Lao Tzu isn't similar to what some people understand, that is, to be negative and passive and to do nothing. He once said, "to behave according to the nature, then the world will be tranquil" (Chapter 3), "if one can achieve the state of inaction, then everything is possible" (Chapter 48), and "a Saint does nothing, so he won't bring about anything" (Chapter 64), etc. As a matter of fact, according to Lao Tzu, "inaction" is positive in two meanings. Firstly, "inaction" is a means, and "action" is a purpose. Secondly, to leave something undone and to leave something done.

\section{3.}

As for contemporary managers, what kind of enlightenments can they acquire from thoughts by Lao Tzu? In the author's point of view, there are primarily the following three aspects:

A manager should lay stress on moral management and social marketing. The so-called moral management means focusing on cultivating, developing and utilizing moral resources of an organization in management, and improving moral quality of a member so as to promote realization of the organization target. As for an enterprise, the core of implementing moral management is to handle well its relationship with stakeholders (such as consumers, competitors, and employees, etc), and to perform its moral responsibility. Any enterprise is an important component of the social organism. As an economic organization, pursuit of benefit maximization is totally rational, but meanwhile, the enterprise is a social organization, so it should also assume social responsibilities and consider social interests. Particularly, with development of market economy and progress of the society, the public pay more attention to moral image of an enterprise, and has more demands upon the enterprise, so influences of moral management on the long-term development of the enterprise becomes more prominent day by day. If an enterprise blindly considers its own interests, then it will finally be abandoned by its stakeholders and be eliminated by the market. The major means to implement moral management is to enhance moral level of an organization, and to model moral image of the organization by means of decision-making, leadership, stimulation and control, etc. Moral quality of a member directly determines moral management level of an organization. It is difficult to imagine that a team of members without correct moral recognition and belief, good moral ability and habit can perform its moral obligation. Furthermore, the current market competition is becoming more and more dependent on quality and image of an enterprise, among which moral quality and moral image is the most important. Therefore, an enterprise should build a team of members with high moral quality through persistent moral management and should win competitive advantages with moral advantages, which exactly corresponds with the thought of Lao Tzu, that is, "to gain victory without struggle" (Chapter 73), which is a thought of conquering the unyielding with the yielding.

The theoretical foundation of market marketing is the theory of limited sovereignty of consumers, whereas the theoretical foundation of social marketing is to expand consumers to relevant social public. In addition to legal restraint, desire and demand of part of customers may run counter to social morality and interests of other public. Satisfaction of their demand might go back on social morality and damage interests of other public. Meanwhile, that is more a harm than good to these customers and even has nothing good, while these demands can usually bring considerable benefits to an enterprise. Besides, even if demand of a customer is above criticism, when production and operation of an enterprise corresponds with legal regulations, it also directly or indirectly influences the ecological status, surrounding environment, social morality tendency or healthy growth of adolescents. Under such a circumstance, choice and decision of an enterprise can better reflect the basic guiding ideology that dominates its production and operation. Quite lots of enterprises give up commercial opportunities that are profitable but don't go against environmental protection and social civilization, and quite lots of enterprises take the initiative to develop products that are high in cost but are helpful to reduce pollution and to save natural resources. All these behaviors have exceeded the scope of customer demand and commercial opportunity in their general meanings, have taken into consideration interests of an enterprise, 
its customers and the society, and have furthermore, reflected connotation of social marketing.

A manager should concentrate on "soft management", which is compared with hard management. The guiding ideology of hard management is the scientific management theory by Taylor, which stresses strict regulations and external supervision. The so-called soft management mainly refers to building perfect organizational atmosphere and establishing a harmonious interpersonal relation through cultivating common values so as to motivate people's enthusiasm. In management, strict regulation and supervision is extremely necessary, but after all, it cannot pay attention to all sides of a matter, and there is always a loophole for people to take advantage of, and what's more, it is difficult to adapt to contemporary complicated and changeable management environment which varies with each individual. Thus, it is difficult to stimulate and satisfy such high-level spiritual demands of self-esteem and self-realization. Too particular stress on hard management may seriously repress and bruise enthusiasm and creativeness of organizational members, and may cause the phenomenon of "Whenever there is a rule, there is a way to get around it", which will in turn result in retortion and tension of relations between leaders and employees. The principle of soft management is to understand, to care, to trust, to respect, to strengthen organizational cohesion and centripetal force, and to encourage organizational members to make all-out efforts to realize the target of the organization. As a manager, he should not only make the best use of legitimate power, and power of reward and punishment, but should perform his expert power, and especially the referent power, so they should influence and lead his employees with personal charm and should stimulate enthusiasm of his employees. In addition, a manager should learn to authorize and employ employees, and should try to create a relax environment for his subordinates to develop their intelligence and wisdom to a greatest extent. In a way, soft management is "to treat with the world from the perspective of inaction and to implement cultivation without words" (Chapter 2).

A manager should put "green management" into practice. Green management of an enterprise refers to an operational activity which integrates environmental protection into the entire process of its operation and management, and which combines environmental protection and enterprise development into one whole. At the time when human beings create unprecedented wealth, the ecological environment of the earth is damaged and becomes deteriorated day by day, which reduces life quality of human beings to a great extent and which poses a threat to their future survival. People come to realize that they should not be the dominator of the nature, but should realize a harmonious relation with the nature and also a sustainable development. In June 1992, United Nations Conference on Environment and Development passed $<<$ Agenda 21>>, which symbolized that the world was gradually stepping into a "green era" that lays stress both on social economy and ecological environmental protection, such as green products, green technology, green tourism, green design and cleaner production, green marketing, green accounting and green auditing, etc. As a manager of an enterprise, he is duty-bound to assume heavy burden of environmental protection, including rational utilization of resources, reduction on consumption, control over pollution, following national law and policy on environmental protection, improvement of employees' consciousness of environmental protection, promotion of environmental protection technology, development of environmental protection industry, increase of investment in environmental protection, and participation and support in social public benefit activities, etc. Lao Tzu's thoughts of "harmony between man and nature", "The Tao [Way] follows nature" and "manifestation of plainness, embrace of simplicity" are helpful for us to carry out "green management".

"To control currently existing things with established "Tao"" (Chapter 14). Thoughts of management ethics of Lao Tzu over two thousand years ago are precious wealth to managers nowadays. Of course, some thoughts contain negative factors, such as, his views of "inaction" and "non-struggle" are sometimes absolutized. Furthermore, thoughts of management ethics by Lao Tzu have great discrepancy from thoughts of management ethics in a contemporary meaning, and even have essential difference. Therefore, at the time when we borrow his thoughts, we should also pay attention to eliminating irrational factors and make a modernized conversion.

\section{References}

(1990). Explanation of Tao Te Ching by Colloquial Language. Tianjin Ancient Classic Bookstore, March, $1^{\text {st }}$ Edition.

Chen, Bingfu \& Zhou, Zucheng. (2000). An Introduction to Corporate Ethics. Nankai University Press, May, $1^{\text {st }}$ Edition.

Su, Yong. (1998). Management Ethics. Orient Press Center, May, $1^{\text {st }}$ Edition.

\section{Notes}

Note 1. Zhou, Zucheng. (1999). Integration of Management and Ethics --- Profound Revolution of Operational Thoughts. Nankai Journal, Philosophy and Social Science Edition, $3^{\text {rd }}$ Edition.

Note 2. Yang, Xianju. (1994). Lao Tzu and Business Management. China Renmin University Press, March, $1^{\text {st }}$ Edition, p20.

Note 3. idem, p100. 